\title{
Impaired left ventricular filling in hypertensive left ventricular hypertrophy as a marker of the presence of an arrhythmogenic substrate
}

Paolo Palatini, Giuseppe Maraglino, Valentina Accurso, Maurizio Sturaro, Giovanni Toniolo, Patrizia Dovigo, Stella Baccillieri

\begin{abstract}
Objective-To assess the prevalence of ventricular late potentials and ventricular tachycardia in hypertensive subjects with left ventricular hypertrophy and to study their relation to clinical characteristics.

Setting-Teaching and general hospital in Padua.

Methods-107 hypertensive subjects with echocardiographic signs of left ventricular hypertrophy were studied with signal averaged electrocardiography and 24 hour Holter monitoring. Signal averaged electrocardiogram analysis was performed with high pass filters of $25 \mathrm{~Hz}$, $40 \mathrm{~Hz}$, and $80 \mathrm{~Hz}$. Ventricular late potentials were considered to be present if at least two determinants of the signal averaged electrocardiogram were abnormal in one of the three filters. 70 normotensive subjects served as age matched controls.
\end{abstract}

Results-25\% (27) of the hypertensive subjects and $6 \%$ (four) of the controls showed late potentials on signal averaged electrocardiography $(P<0.0001)$. The hypertensive subjects with late potentials had a higher prevalence of ventricular tachycardia $(33 \%, 9 / 27)$ than those without late potentials $(13 \%, 10 / 80$; $P=0.035)$. Twenty nine per cent $(31 / 107)$ of the hypertensive subjects had an inversion of the early to atrial filling velocity (E/A ratio < 1) on Doppler analysis of transmitral flow. Within this group the percentage of subjects with late potentials $(55 \%, 17 / 31)$ and ventricular tachycardia $(42 \%, 13 / 31)$ was much greater than that within the group of subjects without an inverted $E / A$ ratio $(13 \%, 10 / 76$ (P < $0.0001)$ and $12 \%, 9 / 76(P=0.001)$ respectively). In a multivariate analysis only the E/A ratio was related to the presence or absence of either late potentials $(P=$ $0.0001)$ or ventricular tachycardia $(P=$ $0 \cdot 0008)$. Both late potentials and ventricular tachycardia were unrelated to left ventricular mass, geometry, and systolic performance.

Conclusions-A relation was found between the occurrence of ventricular tachycardia and the presence of late potentials in hypertensive subjects with left ventricular hypertrophy. Impaired left ventricular filling was the main marker for the arrhythmogenic substrate present in this disease.

(Br Heart f 1995;73:258-262)

Keywords: ventricular late potentials, ventricular tachycardia, left ventricular hypertrophy, hypertension

Several studies have shown that hypertensive patients with left ventricular hypertrophy are at increased risk of sudden cardiac death. ${ }^{1-3}$ These results led to the hypothesis that ventricular arrhythmias are responsible for this increased mortality. Such patients also have an increased frequency of complex ventricular extrasystoles including ventricular tachycardia, ${ }^{4-7}$ but the role of these arrhythmias is not established.

In the past few years the study of ventricular late potentials has proved useful in identifying patients at risk of life threatening ventricular arrhythmias or sudden death after acute myocardial infarction. ${ }^{89}$ Moreover, late potentials are a marker of more serious disease, such as mitral valve prolapse $^{10}$ and dilated $^{11} 12$ or hypertrophic ${ }^{13}$ cardiomyopathy. Much less is known about the prevalence and clinical significance of late potentials in hypertensive left ventricular hypertrophy, as only a few data drawn from small groups of subjects have been published. ${ }^{14-17}$

Our aims were $(a)$ to assess the prevalence of late potentials in a large population of subjects with mild to severe hypertension and echocardiographic signs of left ventricular hypertrophy and (b) to study the relation between late potentials, the occurrence of ventricular tachycardia, and various clinical characteristics.

\section{Patients and methods}

SUBJECTS

The study population consisted of 107 consecutive patients with mild to moderate hypertension (73 men and 34 women; mean age 57 (SD 17) years) and echocardiographic signs of left ventricular hypertrophy (see later). Their mean blood pressure was 171 (23)/106 (17) mm Hg. Antihypertensive treatment, if any, was withdrawn at least two weeks before the start of the study. No patient had angina or previous myocardial infarction. 
Table 1 Mean (SD) measurements on signal averaged echocardiography in 107 hypertensive subjects according to presence or absence of ventricular late potentials

\begin{tabular}{llc}
\hline & \multicolumn{2}{c}{ Ventricular late potentials } \\
\cline { 2 - 3 } & Present $(n=27)$ & Absent $(n=80)$ \\
\hline QRS duration (ms): & $107(30)$ & $89(13)$ \\
Standard & $139(18)$ & $119(16)$ \\
Filtered: & $129(20)$ & $109(14)$ \\
$25 \mathrm{~Hz}$ & $120(22)$ & $97(14)$ \\
$40 \mathrm{~Hz}$ & & \\
$80 \mathrm{~Hz}$ & $43(16)$ & $114(63)$ \\
$\mathrm{RMS} \mathrm{40}$ & $26(21)$ & $60(27)$ \\
$25 \mathrm{~Hz}$ & $12(8)$ & $34(18)$ \\
$40 \mathrm{~Hz}$ & $\mu \mathrm{V}(\mathrm{ms})$ & $18(5)$ \\
$80 \mathrm{~Hz}$ & $23(15)$ & $25(8)$ \\
Duration of signals $<40$ & $34(14)$ & $24(8)$ \\
$25 \mathrm{~Hz}$ & $46(17)$ & \\
$40 \mathrm{~Hz}$ & & \\
$80 \mathrm{~Hz}$ &
\end{tabular}

40 , root mean square amplitude in the last $40 \mathrm{~ms}$ of the filtered QRS.

Patients with bundle branch block were excluded from the study.

Seventy healthy subjects (48 men and 22 women) with a mean age of 57 (16) years served as controls. Forty of them (27 men and 13 women, mean age 57 (15)) underwent echocardiographic examination.

\section{AMBULATORY ELECTROCARDIOGRAPHIC} RECORDING

III Late potentials No late potentials
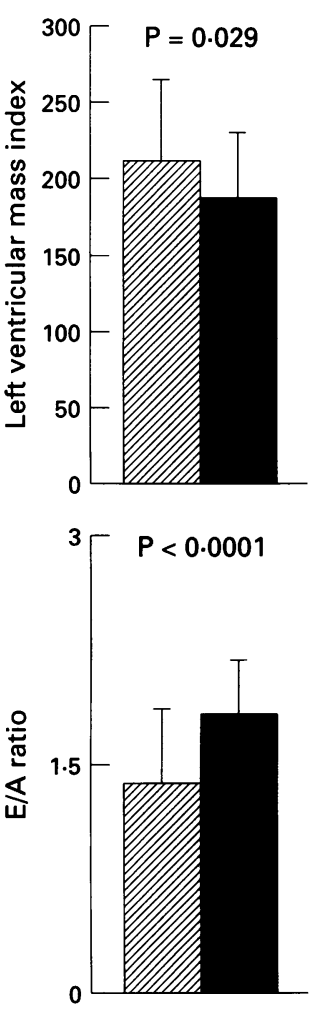

Figure 1 Left ventricular mass index $\left(\mathrm{g} / \mathrm{m}^{2}\right)$ and $E / A$ ratio in 107 hypertensive subjects with left ventricular hypertrophy according to presence $(n=27)$ or presence $(n=27)$ or
absence $(n=80)$ of ventricular late potentials on signal averaged electrocardiography.
We used a two channel ICR 7200 Holter recorder (Instruments for Cardiac Research, Liverpool, USA) or a 90250 Spacelabs recorder (Spacelabs, Redmond, USA) to record electrocardiograms over 24 hours. During the recording subjects carried out their ordinary daily routine. Tapes were scanned on an ICR Holter cardiography system (6201 series) using the procedure described elsewhere. ${ }^{18}$ Patients were divided into two groups according to whether they showed ventricular tachycardia, which was defined as at least three consecutive ventricular extrasystoles (heart rate $\geqslant 100$ beats/minute).

\section{SIGNAL AVERAGED ELECTROCARDIOGRAPHY}

Signal averaged electrocardiograms were recorded with a Marquette Electronics Mac 15 system (Milwaukee, USA). ${ }^{14}{ }^{19}$ Three high pass filters set at 25,40 , and $80 \mathrm{~Hz}$ were used and signals from 400 to 700 beats were averaged to achieve a final noise level of $<0.6$ $\mu \mathrm{V} .^{20}{ }^{21}$ The reason for using these filters is that each has different sensitivities and specificities. ${ }^{22}$ Abnormal values in a signal averaged electrocardiogram were defined according to the criteria of Machac et al: a root mean square voltage of $<25 \mu \mathrm{V}$ for the $25 \mathrm{~Hz}$ filter, $<20 \mu \mathrm{V}$ for the $40 \mathrm{~Hz}$ filter, and $<17 \mu \mathrm{V}$ for the $80 \mathrm{~Hz}$ filter were considered to be abnormal. ${ }^{23}$ For low amplitude signals, values $>32$ ms for the $25 \mathrm{~Hz}$ filter, $>38 \mathrm{~ms}$ for the $40 \mathrm{~Hz}$ filter, and $>42 \mathrm{~ms}$ for the $80 \mathrm{~Hz}$ filter were considered to be abnormal. Corresponding abnormal values for QRS duration were > $114 \mathrm{~ms}, 114 \mathrm{~ms}$, and $107 \mathrm{~ms}$. Ventricular late potentials were considered to be present if at least two determinants of the signal averaged electrocardiogram were abnormal within one of the three filters, provided that QRS complex potentials were visible with an amplitude more than three times the baseline noise. ${ }^{20}$

\section{ECHOCARDIOGRAPHY}

Echocardiograms were recorded using a Hewlett-Packard unit with a $3 \mathrm{MHz}$ transducer, and they were interpreted blindly and independently by two experienced physicians. Echocardiographic data were calculated according to the procedure described elsewhere. ${ }^{418}$ Left ventricular mass was calculated according to the method of Devereux and Reichek ${ }^{24}$ and was normalised to body surface area. Men with a left ventricular mass index > $134 \mathrm{~g} / \mathrm{m}^{2}$ and women with a left ventricular mass index $>110 \mathrm{~g} / \mathrm{m}^{2}$ were said to have left ventricular hypertrophy. The ratio of intraventricular septum thickness and posterior wall thickness (h) to left ventricular diastolic diameter ( $r$ ) was calculated to distinguish between concentric $(h / r \geqslant 0.45)$ and eccentric $(\mathrm{h} / \mathrm{r}<0.45)$ left ventricular hypertrophy.

Left ventricular diastolic filling was studied by means of Doppler analysis of transmitral flow. ${ }^{25}$

Peak early and atrial velocities and the ratio of early to atrial velocity (E/A) were calculated.

\section{STATISTICS}

Values were expressed as means (SD). Student's $t$ test for unpaired observations was used for the comparisons of the numerical variables. $\chi^{2}$ Analysis was performed to compare the categorical variables. The association between various measures of the signal averaged electrocardiogram and echocardiographic data was assessed by the Pearson product-moment correlation test. To assess what clinical variables influenced the occurrence of late potentials and of ventricular tachycardia, backward stepwise logistic regression analysis (Wald method) was performed, using late potentials (positive or negative) and ventricular tachycardia (present or absent) as the dependent variables and left ventricular mass index, the $h / r$ ratio, the $E / A$ ratio, ejection fraction, age, and sex as the independent variables (SPSS-PC program). The $P$ values used for entry and removal of variables were set at 0.05 and $0 \cdot 10$, respectively.

A P value of $<0.05$ was considered to be significant.

\section{Results}

\section{ECHOCARDIOGRAPHIC FINDINGS}

Left ventricular mass index $\left(\mathrm{g} / \mathrm{m}^{2}\right)$ was $194 \cdot 7$ $(47 \cdot 5)$ in the 107 hypertensive subjects $(193.4$ $(47 \cdot 2)$ in the 73 men and $197 \cdot 4(48 \cdot 8)$ in the 34 women). Mean ventricular end diastolic diameter was $54(5) \mathrm{cm}$ and the $\mathrm{h} / \mathrm{r}$ ratio 0.47 $(0.08)$. Left ventricular ejection fraction was $59 \%(5 \%)$ and the E/A ratio $1 \cdot 71(0.45)$. No subject had an ejection fraction lower than $40 \%$.

In the 40 normotensive controls in whom echocardiographic data were acquired the 
Table 2 Mean (SD) findings on echocardiography in 107 hypertensive subjects according to presence or absence of tachycardia

\begin{tabular}{llcl}
\hline & \multicolumn{2}{l}{ Ventricular tachycardia } \\
\cline { 2 - 4 } & Present $(n=19)$ & Absent $(n=88)$ & P value \\
\hline Left ventricular mass index & $216(56)$ & $189(44)$ & 0.025 \\
E/A & $1.33(0.55)$ & $1.81(0.45)$ & $<0.0001$ \\
h/r & $0 \cdot 46(0.13)$ & $0.47(0.07)$ & NS \\
Left ventricular ejection fraction $(\%)$ & $56.7(5.0)$ & $59.3(5.4)$ & NS \\
\hline
\end{tabular}

$\mathrm{E} / \mathrm{A}$, early to atrial maximal velocity of transmitral flow at Doppler analysis.

$\mathrm{h} / \mathrm{r}$, interventricular septum thickness plus posterior wall thickness in diastole divided by end diastolic left ventricular internal diameter.

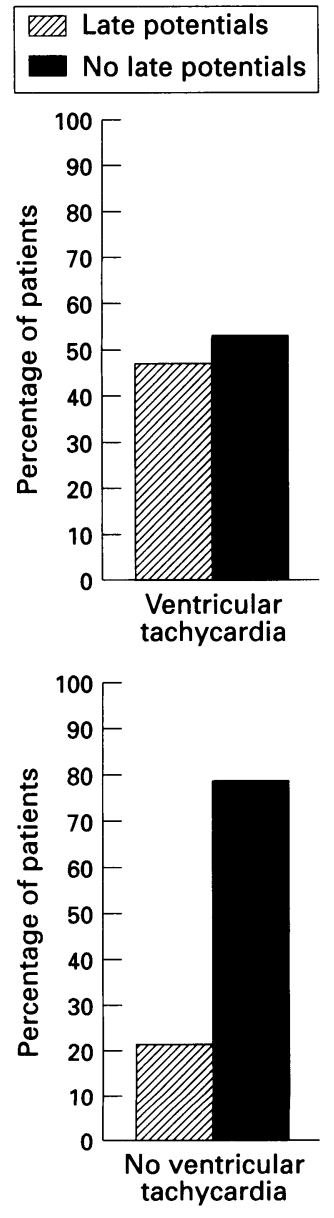

Figure 2 Prevalence of ventricular late potentials among 19 hypertensive subjects with ventricular tachycardia and 88 without such tachycardia. mean left ventricular mass index was significantly smaller $(106 \cdot 2(15 \cdot 2) ; \mathrm{P}<0.0001)$

PREVALENCE OF VENTRICULAR LATE POTENTIALS Twenty seven patients $(25 \%)$ and four controls $(6 \%)$ had ventricular late potentials on signal averaged electrocardiography, a difference which was highly significant $(P<$ 0.0001 ).

Among the hypertensive patients the prevalence of late potentials was slightly but not significantly higher in men $(29 \%, 21 / 73)$ than in women $(18 \%, 6 / 34)$. Age was also unrelated to the prevalence of late potentials, which were present in $25 \%(19 / 77)$ of the subjects who were older than 50 and in $27 \%$ $(8 / 30)$ of those who were 50 or younger. Table 1 shows the signal averaged electrocardiographic measurements in the patients according to the presence of late potentials.

PREVALENCE OF VENTRICULAR ARRHYTHMIAS Eighty four hypertensive patients $(79 \%)$ had at least one ventricular ectopic beat during recording over 24 hours. Twenty of them $(19 \%)$ showed isolated ventricular extrasystoles $>500 / 24 \mathrm{~h}, 24(22 \%)$ multifocal ectopic activity, $21(20 \%)$ ventricular couplets, and 19 (18\%) non-sustained ventricular tachycardia. Ventricular tachycardia always consisted of a short run of three to six ventricular beats, with a heart rate of 130 to 180 beats/minute.

RELATION BETWEEN VENTRICULAR LATE POTENTIALS AND ECHOCARDIOGRAPHIC FINDINGS

Left ventricular mass index was higher in the hypertensive subjects with late potentials than in those without (figure 1). The percentage of men and women did not differ between the two groups $\left(\chi^{2}=1.52 ; \mathrm{P}=0.21\right)$. The $\mathrm{h} / \mathrm{r}$ ratio was similar in the subjects with $(0.477$ $(0.15))$ and without $(0.472(0.048))$ late potentials. Left ventricular ejection fraction was also similar in the two groups $(57.5 \%$ $(6.8 \%))$ in the subjects with late potentials and $59 \cdot 2 \%(4.6 \%)$ in those without). However, the E/A ratio was far lower in the patients who had late potentials on signal averaging (figure 1).

RELATION BETWEEN VENTRICULAR TACHYCARDIA, ECHOCARDIOGRAPHIC FINDINGS, AND VENTRICULAR LATE POTENTIALS

The 19 patients with ventricular tachycardia had a greater left ventricular mass and a lower $\mathrm{E} / \mathrm{A}$ ratio than those without (table 2 ). The $\mathrm{h} / \mathrm{r}$ ratio and left ventricular ejection fraction were not different in the two groups.

Compared with the patients without late potentials, the patients with late potentials more often showed ventricular tachycardia on Holter monitoring. Overall, 13\% (10/80) of those without late potentials had ventricular tachycardia compared with $33 \%(9 / 27)$ of those with late potentials $(P=0.035)$. Conversely, late potentials were more frequent in the subjects with ventricular tachycardia $(47 \%, 9 / 19)$ than in those without $(21 \%, 18 / 88)$ (figure 2$)$.

The percentage of late potentials did not differ according to the number of ventricular extrasystoles ( $\geqslant$ or $<500 / 24 \mathrm{~h}$ ).

Thirty one subjects $(29 \%)$ manifested an inversion of the E/A ratio on Doppler analysis of transmitral flow; the remaining $76(71 \%)$ had an $\mathrm{E} / \mathrm{A}$ ratio $\geqslant 1$.

The prevalence of late potentials was $55 \%$ (17 patients) and that of ventricular tachycardia $42 \%$ (13) in the patients with an inverted E/A ratio. These prevalences were far greater than those in the subjects without an inverted E/A ratio (13\% (10/76) and $12 \%(9 / 76)$, respectively) (fig 3 ).

\section{PEARSON CORRELATION COEFFICIENTS}

Table 3 shows the association between signal averaged electrocardiographic parameters and the E/A ratio and left ventricular mass. The E/A ratio correlated with $Q R S$ duration and root mean square amplitude in the last $40 \mathrm{~ms}$ of the QRS with all filters of analysis, and with low amplitude signals with the $80 \mathrm{~Hz}$ filter.
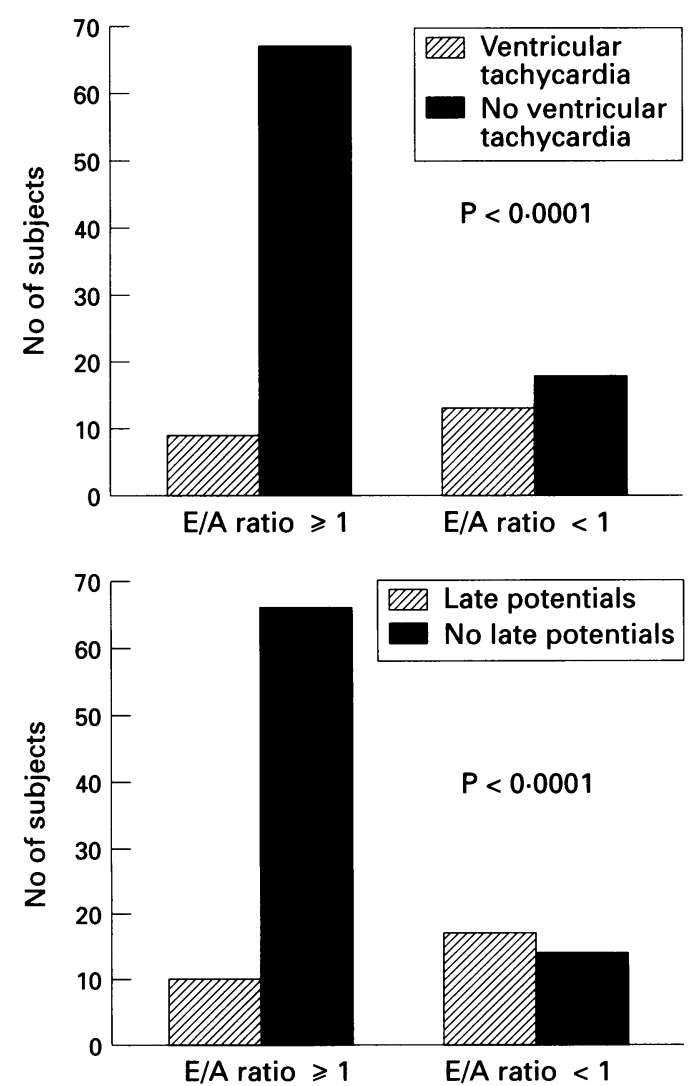

Figure 3 Numbers of hypertensive subjects $(n=107)$ with ventricular late potentials and ventricular tachycardia according to whether their E/A ratio was $\geqslant 1$ or $<1$. 
Table 3 Correlation coefficients between signal averaged electrocardiographic parameters and $E / A$ ratio and left ventricular mass

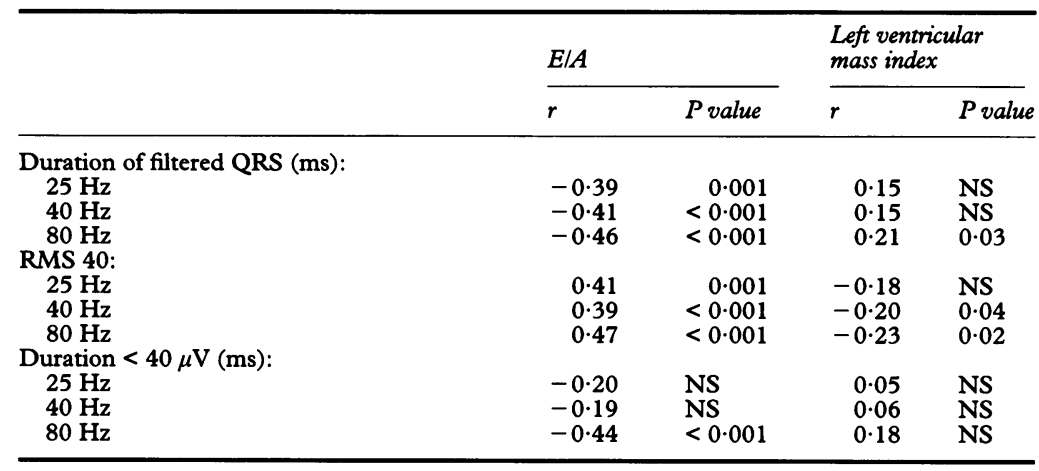

E/A, ratio of early to atrial maximal velocity of transmitral flow.

RMS 40, root mean square amplitude in the last $40 \mathrm{~ms}$ of the filtered QRS.

These relations, however, explained only $15 \%-22 \%$ of the variance. Left ventricular mass index showed a weaker association with the electrocardiographic parameters, which was limited to QRS duration with the $80 \mathrm{~Hz}$ filter and to root mean square amplitude in the last $40 \mathrm{~ms}$ of the QRS with the $40 \mathrm{~Hz}$ and $80 \mathrm{~Hz}$ filters.

\section{MULTIVARIATE ANALYSIS}

When logistic regression analysis was used to determine the independent relation of age, sex, left ventricular mass index, the $h / r$ ratio, ejection fraction, and the $E / A$ ratio to the occurrence of late potentials only the $\mathrm{E} / \mathrm{A}$ ratio showed a significant relation (Wald $\chi^{2}=$ $16.2 ; P=0.0001)$. When the same variables were examined to test their relation to the occurrence of ventricular tachycardia, a significant relation was found only for the $\mathrm{E} / \mathrm{A}$ ratio (Wald $\chi^{2} 11 \cdot 2 ; \mathrm{P}=0.0008$ ).

\section{Discussion}

Patients with hypertensive left ventricular hypertrophy have an increased frequency of complex ventricular extrasystoles, ${ }^{45}$ including non-sustained ventricular tachycardia. ${ }^{67}$ The occurrence of complex ventricular ectopic beats does not, however, necessarily reflect the presence of a genuine arrhythmogenic substrate. We observed an increased frequency of complex ventricular ectopy in professional athletes without underlying cardiac disease, ${ }^{18} 26$ but this finding did not imply an increased risk of sudden cardiac death.$^{27}$ Little is known about the relation between ventricular ectopy detected by 24 hour monitoring and the prognosis in hypertensive patients with cardiac hypertrophy, especially in subjects without left ventricular systolic dysfunction. ${ }^{28}$ Thus, the presence of complex ventricular ectopy in hypertensive subjects with left ventricular hypertrophy does not prove that it heralds fatal electric events. ${ }^{29}$ This enabled us to assess whether an arrhythmogenic substrate exists in hypertensive left ventricular hypertrophy and whether it was related to the occurrence of non-sustained ventricular tachycardia.

In agreement with previous observations in smaller populations ${ }^{14-17}$ the prevalence of ven- tricular late potentials in our hypertensive patients with left ventricular hypertrophy (25\%) was greater than that in a group of healthy normotensive controls studied by the same methods (6\%). To our knowledge, a low prevalence of late potentials in hypertensive left ventricular hypertrophy has been reported only by Pringle et al, who used a more restrictive approach in defining late potentials (three determinants with the $40 \mathrm{~Hz}$ filter). ${ }^{30}$

We found that late potentials were more frequent in the subjects who manifested episodes of ventricular tachycardia on Holter recording than in the subjects with minor forms of ectopy or no arrhythmias. Subjects with late potentials and those with ventricular tachycardia had a greater left ventricular mass index than had those without. In the multiple regression analysis, however, no association was found between late potentials or ventricular tachycardia and the degree of hypertrophy. The only variable which seemed to be independently related to the presence of late potentials was the E/A ratio, which showed a close correlation also with the occurrence of ventricular tachycardia. Moreover, among the subjects with more severe diastolic dysfunction ( $\mathrm{E} / \mathrm{A}$ ratio $<1) 55 \%$ had late potentials and $42 \%$ ventricular tachycardia.

Ventricular late potentials represent low amplitude, fractionated electrical activity and are the markers of an arrhythmogenic substrate, which may be the source of re-entry. ${ }^{31}$ Interstitial fibrosis, which is closely associated with the occurrence of ventricular arrhythmias in hypertensive myocardiopathy, ${ }^{32}$ can result in abnormal impulse propagation throughout the myocardium and lead to re-entry. On the other hand, diffuse or even subendocardial fibrosis rather than the increase in left ventricular mass seems to be the main determinant of impaired left ventricular relaxation in myocardial hypertrophy. ${ }^{33-35}$ Indeed, White et al found no relation between impairment of left ventricular diastolic function and degree of myocardial hypertrophy. ${ }^{36}$ Our results are in keeping with those of the aforementioned studies because the degree of diastolic dysfunction rather than of echocardiographic left ventricular hypertrophy was related to the presence of late potentials. This lack of a relation between left ventricular mass and the occurrence of late potentials has been reported previously. ${ }^{17} 37$

In our study patients who had late potentials were comparable with those who did not in terms of their ventricular ejection fraction, but we emphasise that none of our patients had severe left ventricular systolic dysfunction. The geometry of the left ventricle was also unrelated to the presence of late potentials, the $h / r$ ratio being almost equal in patients with and without late potentials, and not varying according to the presence or absence of ventricular tachycardia. Moreover, in the multiple regression analysis the $h / r$ ratio was totally unrelated to either late potentials or ventricular tachycardia. These results are at variance with those of Galinier et $a l^{14}$ and Franchi et $a l,{ }^{15}$ who found that the prevalence 
of late potentials was greater in subjects with eccentric left ventricular hypertrophy than in those with concentric hypertrophy. However, the difference in our two results is probably the result of the depressed left ventricular systolic performance in eccentric hypertrophy.

The discordance found in some of our patients between the presence of late potentials and the occurrence of ventricular tachycardia deserves a final comment. This finding suggests that the presence of a short run of ventricular tachycardia does not, in itself, imply a re-entrant substrate and that mechanisms other than re-entry are at work in determining ventricular tachycardia in hypertensive myocardiopathy. However, ventricular arrhythmias are not highly reproducible in repeated recordings, ${ }^{38}$ so complex forms of arrhythmias may be missed in a single 24 hour Holter study.

In conclusion, our results show that the prevalence of late potentials and of nonsustained ventricular tachycardia is increased in subjects with hypertensive myocardiopathy. Impaired left ventricular filling rather than the degree of hypertrophy is the main marker of the arrhythmogenic substrate present in this disease and thus might represent a more important risk factor than left ventricular mass for cardiac sudden death. However, left ventricular geometry and systolic function do not seem to influence the ventricular arrhythmogenesis, at least in patients who do not have severe left ventricular systolic dysfunction or left ventricular dilatation.

1 Kannel WB, Gordon T, Castelli WP, Margolis JR Electrocardiographic left ventricular hypertrophy and risk of coronary heart disease: the Framingham study. Ann Intern Med 1970;72:813-22.

2 Kannel WB. Prevalence and natural history of electrocardiographic left ventricular hypertrophy. $\mathrm{Am} \mathcal{f ~ M e d}$ 1983;75(suppl 3A):4-11.

3 Casale PN, Devereux RB, Milner M, Zullo G, Harshfield GA, Pickering TG, et al. Value of echocardiographic measurement of left ventricular mass in prardiographic diovascular morbid events in hypertensive men. Ann Iiovascular morbid events

4 Palatini $P$, Bongiovi $S$, Cordiano R, Munari L, Scanavacca G, Musco A, et al. Ventricular ectopic activity in physically trained

5 Messerli FH, Ventura HO, Elizardi DJ, Dunn FG Frohlich ED. Hypertrophy and sudden death: increased ventricular ectopic activity in left ventricular hypertrophy. $A m \mathcal{F}$ Med 1984;77:18-22.

6 McLenachan JM, Henderson E, Morris KI, Dargie HJ. Ventricular arrhythmias in patients with hypertensive left ventricular hypertrophy. $N$ Engl $\mathcal{f}$ Med 1987;317: 787-92

7 Pringle SD, Macfarlane PW, McKillop JH, Lorumer AR, Dunn FG. Pathophysiologic assessment of left ventricular hypertrophy and strain in asymptomatic patients with essential hypertension. $7 \mathrm{Am}$ Coll Cardiol 1989;13: 1377-81.

8 Simson MB. Use of signals in the terminal QRS complex to identify patients with ventricular tachycardia after myocardial infarction. Circulation 1981;64:235-41.

9 Zimmermann M, Adamec R, Simonin P, Richez J. Prognostic significance of ventricular late potentials in coronary artery disease. Am Heart f 1985;109:725-32.

10 Leclercq JF, Malergue MC, Coumel P. Potentiels tardif et prolapsus valvulair mitral. Arch Mal Coeur Vaiss 1993, 86:285-9.

11 Denereaz D, Zimmermann M, Adamec R. Significance of ventricular late potentials in non-ischaemic dilated cardiomyopathy. Eur Heart f 1992;13:895-901.

12 Mancini DM, Wong KL, Simson MB. Prognostic value of an abnormal signal-averaged electrocardiogram in patients with nonischemic congestive cardiomyopathy. Circulation 1993;87:1083-92.
13 Iannucci $G$, Villani $M$, Giacopello $F$, Giordano $M$ Cangelosi AP, Ciardo AR, et al. Late potentials and hypertrophic cardiomyopathy: report of 25 patients and
review of the literature. G Ital Cardiol 1992;22:281-90.

14 Galinier M, Doazan JP, Albemque JP, Massabuau P, Boubakar D, Puel J, et al. Cardiopathie hypertensive et potentiels tardifs ventriculaires. Arch Mal Coeur Vaiss 1992;85:1095-8.

15 Franchi F, Michelucci A, Padeletti L, Monopoli A, Fabbri G, Cersosino RC, et al. Arrhythmogenesis in left ventricular hypertrophy in mild to moderate essential hypertension. G Ital Cardiol 1992;23:905-18.

16 Gunter Vester E, Kuhis S, Perings C, Ochiulet-Vester J, Strauer BE. Ventricular late potentials in hypertensive patients with and without left ventricular hypertrophy. Eur Heart $\mathcal{F}$ 1993:14:451A

17 Prisant LM, Wylds AC, Carr AA, Gross CM, Flowers NC. Assessment of late potentials in patients with essenNC. Assessment of late potentials in patients with essen-
tial hypertension by the signal-averaged electrocardiotial hypertension by the signal-averaged electrocardiogram with

18 Palatini P, Maraglino G, Calzavara A, Libardoni M, Pessina AC, Dal Palù C. Prevalence and possible mechanisms of ventricular arrhythmias in athletes. Am Heart $\mathcal{F}$ 1985;110:560-7.

19 Lietava J, Kuka P, Dukat A, Balazovjech I. Postexercise monitoring of ventricular late potentials in hypertensive patients. F Hypertens 1991;9(suppl 6):S160-1.

20 Breithardt G, Cain ME, El-Sherif N, Flowers NC, Hombach V, Janse M, et al. Standards for analysis of ventricular late potentials using high resolution or signalaveraged electrocardiography. $\mathcal{F} \mathrm{Am}$ Coll Cardiol 1991; 17:999-1006.

21 Kennedy HL, Bavishi NS, Buckingham TA. Ambulatory (Holter) electrocardiography signal-averaging: a current (Holter) electrocardiography signal-averagin

22 Gomes JA, Winters SL, Stewart D, Targonski A, Barreca P. Optimal bandpass filters for time-domain analysis of the signal-averaged electrocardiogram. Am $f$ Cardiol 1987;60:1290-8.

23 Machac J, Weiss A, Winters SL, Barecca P, Gomes JA. A comparative study of frequency domain and time domain analysis of signal-averaged electrocardiograms in patients with ventricular tachycardia. $\mathcal{F} \mathrm{Am}$ Coll Cardiol 1988;11:284-96.

24 Devereux R, Reicheck N. Echocardiographic determination of left ventricular mass in man. Circulation 1977;55:613-8.

25 Bongiovi S, Palatini P, Macor F, Visentin PA, Pessina AC Age and blood pressure related changes in left ventricular Age and blood pressure related changes in lef

26 Palatini P, Maraglino G, Mos L, Munari L, Ronsisvalle G Calzavara A, et al. Effect of endurance training on Q-T Calzavara $A$, et al. Effect of endurance training on Q-T
interval and cardiac electrical stability in boys aged 10 to interval and cardiac electrical stat

27 Palatini P, Scanavacca G, Bongiovi S, Dall'Agata A, Maraglino G, Mormino P, et al. Prognostic significance of ventricular extrasystoles in healthy professional athletes: results of a 5-year follow up. Cardiology 1993;82 286-93.

28 Coste P, Clementy J, Besse P, Bricaud H. Left ventricular hypertrophy and ventricular dysrhythmic risk in hypertensive patients: evaluation by programmed electrical stimulation. $尹$ Hypertens $1988 ; 6$ (suppl 4):S116-8.

29 Messerli FH. Hypertension, left ventricular hypertrophy, ventricular ectopy, and sudden death. Am $¥$ Hypertens 1993;6:335-6.

30 Pringle SD, Dunn FG, Macfarlane PW, McKillop JH Lorimer AR, Cobbe SM. Significance of ventricular Lorimer AR, Cobbe SM. Significance of ventricular arrhythmias in systemic hypertension with left

31 Breithardt G, Borggrefe M. Pathophysiological mechanisms and clinical significance of ventricular late potennisms and clinical significance of
tials. Eur Heart $\mathcal{f} 1986 ; 7: 364-85$.

32 McLenachan JM, Dargie HJ. Ventricular arrhythmias in hypertensive left ventricular hypertrophy: relationship to coronary artery disease, left ventricular dysfunction and myocardial fibrosis. Am $\mathcal{f}$ Hypertens 1990;3:735-40.

33 Caspari PG, Newcomb M, Gibson K, Harris P. Collagen in the normal and hypertrophied human ventricle. Cardiovasc Res 1977;11:554-8.

34 Hanrath $P$, Mathey DG, Siegert R, Bleifeld W. Left ventricular relaxation and filling pattern in different forms of left ventricular hypertrophy: an echocardiographic study. Am $¥$ Cardiol 1980;45:15-23.

35 Jalil JE, Doering CW, Janicki JS, Pick R, Shroff SG, Weber KT. Fibrillar collagen and myocardial stiffness in the intact hypertrophied rat left ventricle. Circ Res 1989;64: intact hypert

36 White WB, Schulman P, Dey HM, Katz A. Effects of age and 24-hour ambulaty blood pressure on rapid left and 24-hour ambulatory blood pressure on rapid

37 Panagides D, Amabile G, Deharo JC, Audebert C Diiane P, Bory M. Etude des potentiels tardifs Djiane P, Bory M. Etude des potentiels tardifs chez l'hy $1165-8$.

38 Morganroth J, Michelson EL, Horowitz LN, Josephson ME, Pearlman AS, Dunkman WB. Limitations of routine long-term electrocardiographic monitoring to assess ventricular ectopic frequency. Circulation 1978;58: 408-14. 